Winter 2-16-2016

\title{
The Perfect Storm: Examining User Experience and Conducting a Usability Test to Investigate a Disruptive Academic Library Web Site Redevelopment
}

Darren Chase

SUNY Stony Brook, darren.chase@stonybrook.edu

Elizabeth Trapasso

SUNY Stony Brook, elizabeth.trapasso@stonybrook.edu

Robert Tolliver

SUNY Stony Brook, robert.tolliver@stonybrook.edu

Follow this and additional works at: https://commons.library.stonybrook.edu/library_articles

Part of the Library and Information Science Commons

Creative Commons Attribution-Noncommercial 3.0 License

This work is licensed under a Creative Commons Attribution-Noncommercial 3.0 License

\section{Recommended Citation}

Chase, Darren; Trapasso, Elizabeth; and Tolliver, Robert, "The Perfect Storm: Examining User Experience and Conducting a Usability Test to Investigate a Disruptive Academic Library Web Site Redevelopment" (2016). Library Faculty Publications. 1.

https://commons.library.stonybrook.edu/library_articles/1 


\title{
The Perfect Storm: Examining User Experience and Conducting a Usability Test to Investigate a Disruptive Academic Library Web Site Redevelopment
}

This is an Accepted Manuscript of an article published by Taylor \& Francis Group in Journal of Web Librarianship on 02/16/2016, available online: http://www.tandfonline.com/doi/abs/10.1080/19322909.2015.1124740.

DOI: $10.1080 / 19322909.2015 .1124740$

Darren Chase, Elizabeth Trapasso \& Robert Tolliver

\begin{abstract}
The researchers conducted a task-based usability test of the effectiveness of online research beginning on the library Web site homepage. The participants included five university faculty members, six graduate students, and six undergraduate students. All participants reported feeling satisfied with their overall research experience, though most were unable to effectively complete all the research tasks of the test. The researchers identified weaknesses in the approach and process of many participants, and overall usability issues of the library discovery tool and other library Web site pages and research interfaces. Findings indicate the need to strategically incorporate self-service information literacy and research skills help into the library Web site, and to implement navigation and design changes to the library homepage, discovery tool interface, online catalog, and across all the library's Web services.
\end{abstract}

\section{Keywords}

academic libraries, database searching, information literacy, information retrieval, research methodology, user experience, user interfaces, website design

In the fall semester of 2014, researchers at the Stony Brook University (SBU) Libraries conducted a usability test of the effectiveness of online research beginning at the library Web site homepage. During the summer of 2014, the library Web site was redesigned, and it incorporated several changes and enhancements, including the launch of the EBSCO Discovery Service (EDS) and movement from Serials Solutions to the EBSCO Electronic Resource Management System (ERMS). The new Web site design and new online tools and interfaces presented our users with a wholly new online research experience. This article describes the development of the usability test of our discovery service, its administration, and the findings. 


\section{Background}

Planning for the redevelopment of our library Web site began during fall 2013. User experience and feedback from an array of sources was incorporated into the process: the results of a large-scale user survey administered spring 2012, and observations and user feedback from research assistance and course-integrated information literacy instruction sessions.

The 2014 usability test was conducted as one aspect of an evaluation of the overall online user experience precipitated by a "perfect storm" of change in the SBU Libraries Web-scale systems. The new library Web site, EDS implementation, and new and merged ERMS were elements of what was intended to be an enhanced online user experience, albeit a disruptive one. The platform changes will be described in further detail to illuminate the challenges facing both library staff and our users.

A discovery service retrieves results from a single index. The EDS implemented at SBU Libraries features an index that includes two separate online library catalogs, the University Libraries catalog (branded STARS) and the Health Sciences Library catalog, as well as content from most of SBU Libraries' more than 600 research databases. The two catalogs are a vestige of SBU's previous two whole and distinct library organizations: one for the Health Sciences Library and the other for "everything else." While the merger of the two organizations began in 2012, there remained some unknotted systems, most notably the online catalogs. Including more than one online catalog is an atypical feature of an academic library system, and incorporating both catalogs was a significant consideration in successfully implementing EDS.

The complexity of the EDS implementation was increased further by the migration and merger of the two SBU libraries' ERMSs from separate Serials Solutions systems to a single EBSCO ERMS. This migration and merger took place during the beginning of the EDS implementation and generated myriad issues for users adjusting to the new system interface, as well as for SBU Libraries ERMS staff learning and troubleshooting the new system and a single, larger collection, and for the SBU Libraries IT team who were working on the EDS implementation.

The new library Web site was entirely redeveloped and redesigned using the WordPress platform. We decided to move to WordPress from the previous Content Management System (CMS) platform, Drupal, based on a number of compelling conditions. One reason was the lack of support and functionality of many of the Drupal modules used on the Web site (using Drupal 6) with the latest version of Drupal (Drupal 8). The complexity of Drupal also presented barriers for library staff use. WordPress, in contrast, was a familiar platform for many library staff as it had been used for the SBU Libraries News Blog. We investigated the latest version of WordPress and determined that it was robust and dynamic enough to support the development needs of the new site. Because the latest version of WordPress uses HTML 5, it is responsive, dynamic, and mobile-ready.

The purpose of the investigation was to gather evidence to evaluate the effectiveness of the library Web site (specifically the newly-implemented discovery tool) as a self-service research 
portal. The research project investigated the online user experience of individuals representing the library's prime constituent groups: undergraduate students, graduate students, and faculty. Because the Web site redesign incorporated features that support undergraduate and unmediated research, the investigation team expected to gather evidence of undergraduate success in using the Web site, along with effective use by graduate students and faculty who tend to be practiced, focused users of the library's online resources and services.

\section{Literature review}

In our quest to make our library Web sites more user-friendly and the place to start their research, libraries face the problem of distilling their multiple information resources into a simple and easy-to-understand interface. Luther and Kelly (2011) noted that users need the quality of the library's resources but expect the simplicity that Google provides. However, users are neither aware of nor do they understand the diversity of information resources, including catalogs, databases, and online journals, that can be found through the libraries' Web site (Brown and Yunkin 2014; Swanson and Green 2011). Troy Swanson and Jeremy Green (2011) noted that users searched whatever search box was presented to them. Because library Web sites must address this diversity of resources, Web site designs sometimes include tradeoffs that may benefit some users more than others (Brown and Yunkin 2014).

Discovery tools are one aspect of modern library Web site designs that hope to provide single-search box access to most library resources with the Google-like experience users want, but with the scholarly resources that libraries provide. Thomsett-Scott and Reese (2012), in their review of the literature on library discovery tools, found that the ability to narrow search results, speed, ease of use, and relevancy of results were common elements that users liked about library discovery tools. For this study, a review of the literature identified three general themes related to library Web site redesign and usability studies: usability of the search interface, interpreting the search results, and the impact of discovery tools on instruction.

\section{Usability of the search interface}

Usability studies of library Web sites over the last few years show the continuing challenges of getting users started with the right search tool. Should users start with a single-search box discovery tool, the catalog, or a subject-specific database? Cassidy and colleagues (2014) found that test volunteers were more successful with author searching and known-book searching tasks when using the library catalog than they were with their discovery tool (EDS), but were more successful using the EDS for known-article searches and topic searches than when using other library resources. The authors also found that students were more satisfied with the EDS, even though they were less successful on some tasks than with the library catalog. Gross and Sheridan (2011), in usability testing after their Web site redesign, found that 80 percent of the time the participants used their new discovery tool to begin 
their searches. They posed the question as to whether the single-search box was limiting users' willingness to use other library resources. Jody Condit Fagan and colleagues (2012) noted that users did not seem to understand when a discovery tool, the library catalog, or a subject-specific database would be the best tool for their information needs. They noted that catalogs and subject-specific databases still performed some tasks better. Additionally, they discussed when users should be directed to one tool versus another, and how do "library websites begin to make sense of the current state of library search systems?" (Fagan et al. 2012, 103).

The use of facets and limiting functions such as radio buttons have become an important aspect of library discovery tools and catalogs, on both the initial search pages and on the results pages. One finding of particular interest in Olson's (2007) study was that advanced researchers identified relevant material that they had not previously found without facets. Cassidy and colleagues (2014) found that students overwhelmingly noticed the radio button limiters on their EDS search page and used these correctly in their searches. However, the students did have trouble with the facets on the EDS results page: They would generally not click on facets to expand options or use facets that required scrolling down the results page. More than half the students either did not notice or did not use the facets. In another study, volunteers also did not scroll down far enough to see the complete list of facets (Thompson, Obrig, and Abate 2013). This study also found facet selections that carried forward to subsequent searches were another potential problem. Thomsett-Scott and Reese (2012), in their review article, indicated that several studies found issues with facets and that they must be "open" so that users can see what options are available. Despite these potential problems, users generally like the ease with which they can refine their searches using facets and other limiters (Fagan et al. 2012; Olson 2007; Thompson et al. 2013; ThomsettScott and Reese 2012). In Thompson and colleagues (2013), post-search questions revealed that the ability to narrow search results with limiter/facet options was the feature that volunteers liked best.

\section{Users' ability to interpret the search results}

One of the first results-related issues that users may face with discovery tools are the overwhelming number of search results (Thomsett-Scott and Reese 2012). Too many results was the primary reason indicated for not teaching Serial Solutions' Summon as reported by Buck and Mellinger (2011). In addition to the sheer number of results, the many features of the discovery tool system left some users confused (Fagan et al. 2012; Gross and Sheridan 2011).

One area of concern in several studies involved relevancy issues in search results returned by discovery tools. Buck and Mellinger (2011) found that 45 percent of librarians indicated that lack of relevancy in results was one of the reasons they did not teach the Summon integrated discovery tool in their instruction sessions. Cassidy and colleagues (2014), who conducted a usability test with the EDS, found that searches for specified books often returned critical reviews of the book before the record for the actual book. They also found issues with author searches returning records for items with the individual as second author 
before results as first author. Additionally, they found that the results of some keyword searches were dominated by book records, while other search results were dominated by article records. In another study, during the early stages of usability testing, a librarian focus group identified relevancy ranking as an area needing improvement (Thompson et al. 2013). In the same study, this issue was also identified by test volunteers who noted that the difficulty in getting a good set of results for their searches was their least favorite thing about using EDS.

Identifying and accessing full text of articles was a problem in some studies. Thompson and colleagues (2013) found that their link resolver, Find it @ Himmelfarb?, was too small, and test volunteers could not locate where to go to get full-text articles. Pinkas and colleagues (2014) found that participants tended to click on rich links or PDF links when present, but they did not use the "Find It" link resolver to get to full text, thinking it may go solely to interlibrary loan. As a result of these findings, the researchers decided to use the link resolver button throughout, instead of rich links, to have a consistent appearance across all resources.

\section{Discovery tools' impact on instruction}

Implementation of discovery tools has impacted library instruction. Instruction librarians must decide how and when to use the library's discovery tool in instruction. Helping users understand which library tools to use for different information needs and how to most effectively use these tools is still an important area for library instruction. Thomsett-Scott and Reese (2012) in their review article found that several usability studies indicated that students desired some instruction on using discovery tools effectively. Even graduate students and faculty showed a need for guidance in using library resources due to their tendency to stick with the resources they have prior experience with (Kim 2010). Fagan and colleagues (2012) indicated that another area where users need instruction is on how to work with the large number of results that are often returned by discovery tools. Finally, Ansari and Zuberi (2010) reported that a lack of knowledge was one of the primary reasons that faculty in their study gave for not using electronic resources.

\section{Methods}

\section{Usability test development}

The research team developed this usability test to glean information on how patrons were using the SBU Libraries' Web site and to test their success with navigating the Web site and EDS. In order to do this, a set of five questions was developed that the team saw as indicative of the core areas of the library Web site (using the catalog, accessing e-journals, accessing the research databases, distinguishing peer-reviewed articles, and requesting assistance).

(1) Does the library have a book titled, "The World of the Druids"? 
(2) What is the date range for full-text access to the e-journal Scientific American?

(3) Find a selection of databases for doing effective research in the Health Sciences.

(4) Find a peer-reviewed journal article on sustainable agriculture.

(5) Where do you get help with a research question?

\section{User participant groups}

The research team evaluated four groups of SBU Libraries' Web site users: Library faculty, teaching faculty, undergraduate students, and graduate students. Participation was voluntary, and undergraduate and graduate students were treated to refreshments and SBU Library mementos. To promote the project to students, the research team created a sign-up option on the blog for the Library's Web site. In addition, promotional signage was placed in the Library's Central Reading Room encouraging participation. The research team had Library faculty serve as the control group for the study, as it was determined that this group would have the most experience and confidence with using the Library Web site and EDS. All groups were tested in the same setting, the Library computer classroom. There were seven members in the librarian control group, and eighteen members of the test group: seven undergraduates, six graduate students, and five faculty members. For organizational and time-management purposes, the control group completed the test separately from the other participants. The student groups (graduate and undergraduate) were intermixed but were given two separate session options to attend. The faculty group met individually with the research team to complete the testing, as their schedules permitted.

\section{Usability information gathering process}

The researchers provided instructions for completion of the usability test at the beginning of the session. Participants were given a worksheet and were instructed not to record answers on the paper, as screen capture software would record actions and provide evidence of completion. Researchers also instructed participants to keep moving through the activity (even if unsure of an answer), to minimize the number of questions asked during the session, and to note areas of difficulty for patrons. Once participants completed the test, the research team assisted in saving the screen captures to their workstations using SMART Technologies' SMART Recorder software. Recordings were uploaded to a shared Google Drive folder. For security purposes, this Google Drive folder was closed to non-research team members after files were uploaded. 


\section{Rubric scoring}

The researchers were interested in observing how users engaged in the search process using the Library's Web site. The goal was to ascertain the most effective method (fastest time, least amount of clicking through Web pages) to answer the test questions. Depending on the complexity of the question, the amount of effort needed to complete the tasks varied. A task such as seeking online help (Question 5) required a single click of the help button because the answer could be directly found from any page associated with the Libraries' Web site. A task such as locating the database coverage period of an e-journal (Question 2) required (at minimum) four separate steps because the user must click through multiple Web pages to locate the answer. To this end, the research team developed a rubric scoring metric for each question of the test (see Appendix A). Each question was given a numeric value in the rubric based on the number of steps taken to complete the process. A singleclick task, like Question 5, was given a score of 1 (if the user was able to locate the help button) or a 0 if the user was unable to complete the task. A multi-step task, such as Question 2, was scored on a scale of 0 to 4 , based on completion of the task. The user would receive a lesser score if they did not follow all necessary steps to complete the activity. Therefore, higher total scores indicated that participants had been more successful in completing the research tasks efficiently and effectively. The research team accounted for various methods of searching in the rubric to allow for multiple avenues of access (e.g., multiple ways to request help from the Library's homepage). Participants received a rubric score for each question, and then scores were totaled and compared against the control group. Additionally, the completion times for each user group were averaged and compared to examine the time spent on task.

\section{Formulating feedback}

Researchers also wanted to gather feedback on participants' overall search experience. Participants answered two questions about the effectiveness of the new search tools and how they could be improved.

(1) In creating the SBU Library research Web tools, what did we do really well?

(2) What can we do to be even better?

Feedback was requested from participants either verbally, during and after the session, or via e-mail on a voluntary basis.

\section{Findings}

\section{Previous library experience}

Because they were library employees, the control group had significant knowledge of the subject matter and familiarity with the library Web site. However, teaching faculty members 
varied in their use of library resources prior to this study. Some had little experience with searching databases independently, while others felt extremely confident in their ability to navigate resources such as EBSCOhost and JSTOR using the library's homepage. One instructor stated that she regularly pointed her students to EBSCOhost from the library Web site, as it provided a wealth of interdisciplinary search options from one central source. The student groups were not asked about their experiences with using the library resources prior to the activity, as the research team anticipated participation from varied academic standings (freshman through advanced-level graduate students).

\section{Overall search success and feedback}

Not surprisingly, the control group averaged the highest overall rubric scores and completed the testing in the shortest amount of time (see Table 1). Of note, for Question 1, two of the seven control participants used the standard catalog (STARS) to locate books in the collection instead of the discovery service (EDS) search tool because the catalog provided quicker access to the record information. This strategy could be attributed to library staff members' familiarity with the STARS interface as compared to EDS. Also, each control group member was successful in accessing the required research databases from Question 3, but went about the process in a myriad of ways. For example, the health science library staff were able to locate the required materials in the fastest time, with the fewest number of links to click through. This group uses and visits these resources more frequently than other non-health science librarians, and consequently are more proficient at accessing these particular resources. 
Table 1. Usability test scores and times by individual participant.

\begin{tabular}{|c|c|c|c|c|c|c|c|c|}
\hline User & $\begin{array}{l}\text { Q1 Value } \\
(0-4)\end{array}$ & $\begin{array}{l}\text { Q2 Value } \\
(0-4)\end{array}$ & $\begin{array}{l}\text { Q3 Value } \\
(0-3)\end{array}$ & $\begin{array}{l}\text { Q4 Value } \\
(0-2)\end{array}$ & $\begin{array}{l}\text { Q5 Value } \\
(0-1)\end{array}$ & Time & Total & $\begin{array}{l}\text { Average } \\
\text { Time per } \\
\text { User Group }\end{array}$ \\
\hline 1 Faculty & 0 & 0 & 0 & 0 & 0 & $4: 33$ & 0 & \\
\hline 2 Faculty & 4 & 4 & 3 & 2 & 1 & 13.04 & 14 & \\
\hline 3 Faculty & 2 & 4 & 1 & 2 & 1 & $8: 30$ & 10 & \\
\hline 4 Faculty & 3 & 4 & 2 & 2 & 1 & 13.58 & 12 & \\
\hline 5 Faculty & 4 & 4 & 3 & 2 & 1 & $7: 04$ & 14 & $9: 25$ \\
\hline 1 Control & 2 & 4 & 3 & 2 & 1 & $4: 00$ & 12 & \\
\hline 2 Control & 4 & 4 & 3 & 2 & 1 & 5:15 & 14 & \\
\hline 3 Control & 2 & 4 & 3 & 2 & 1 & $5: 20$ & 12 & \\
\hline 4 Control & 1 & 4 & 3 & 2 & 1 & $4: 15$ & 11 & \\
\hline 5 Control & 3 & 4 & 3 & 2 & 1 & $2: 20$ & 13 & \\
\hline 6 Control & 4 & 4 & 3 & 2 & 1 & $2: 30$ & 14 & \\
\hline 7 Control & 1 & 4 & 3 & 2 & 1 & S:02 & 11 & $4: 06$ \\
\hline 1 UG student & 2 & 4 & 0 & 0 & 0 & $8: 02$ & 6 & \\
\hline 2 UG student & 2 & 0 & 0 & 1 & 1 & $9: 18$ & 4 & \\
\hline 3 UG student & 1 & 1 & 2 & 2 & 1 & $5: 12$ & 7 & \\
\hline 4 UG student & 1 & 3 & 0 & 1 & 0 & $8: 20$ & 5 & \\
\hline 5 UG student & 4 & 4 & 3 & 2 & 1 & $3: 14$ & 14 & \\
\hline 6 UG student & 2 & 1 & 3 & 1 & 1 & 8:06 & 8 & 7:02 \\
\hline $\begin{array}{l}1 \text { Grad } \\
\text { student }\end{array}$ & 3 & 1 & 0 & 2 & 1 & $4: 30$ & 7 & \\
\hline $\begin{array}{l}2 \text { Grad } \\
\text { student }\end{array}$ & 0 & 4 & 3 & 2 & 0 & $5: 37$ & 9 & \\
\hline $\begin{array}{l}3 \text { Grad } \\
\text { student }\end{array}$ & 2 & 4 & 3 & 2 & 1 & 5.00 & 12 & \\
\hline $\begin{array}{l}4 \text { Grad } \\
\text { student }\end{array}$ & 2 & 1 & 3 & 2 & 1 & $4: 00$ & 9 & \\
\hline $\begin{array}{l}5 \text { Grad } \\
\text { student }\end{array}$ & 2 & 1 & 3 & 2 & 0 & $5: 40$ & 8 & \\
\hline $\begin{array}{l}6 \text { Grad } \\
\text { student }\end{array}$ & 2 & 4 & 0 & 1 & 1 & $5: 45$ & 8 & 5.05 \\
\hline
\end{tabular}

Faculty were relatively proficient in their search strategies using the new interface, as they averaged the second highest overall rubric scores (Figure 1). One faculty participant displayed frustration with several questions on the usability test, stating that she would ask a librarian to conduct this type of online researching and not use the EDS. Others were able to successfully complete the activity, but fell into the habit of searching by individual databases instead of using the EDS's singular search feature. While this method is acceptable, it requires multi-step searching and prolongs the time needed to access materials. The approach these faculty took can be attributed to unfamiliarity with the new service. 
Figure 1. Usability test scores with a comparison of performance averages by user groups.

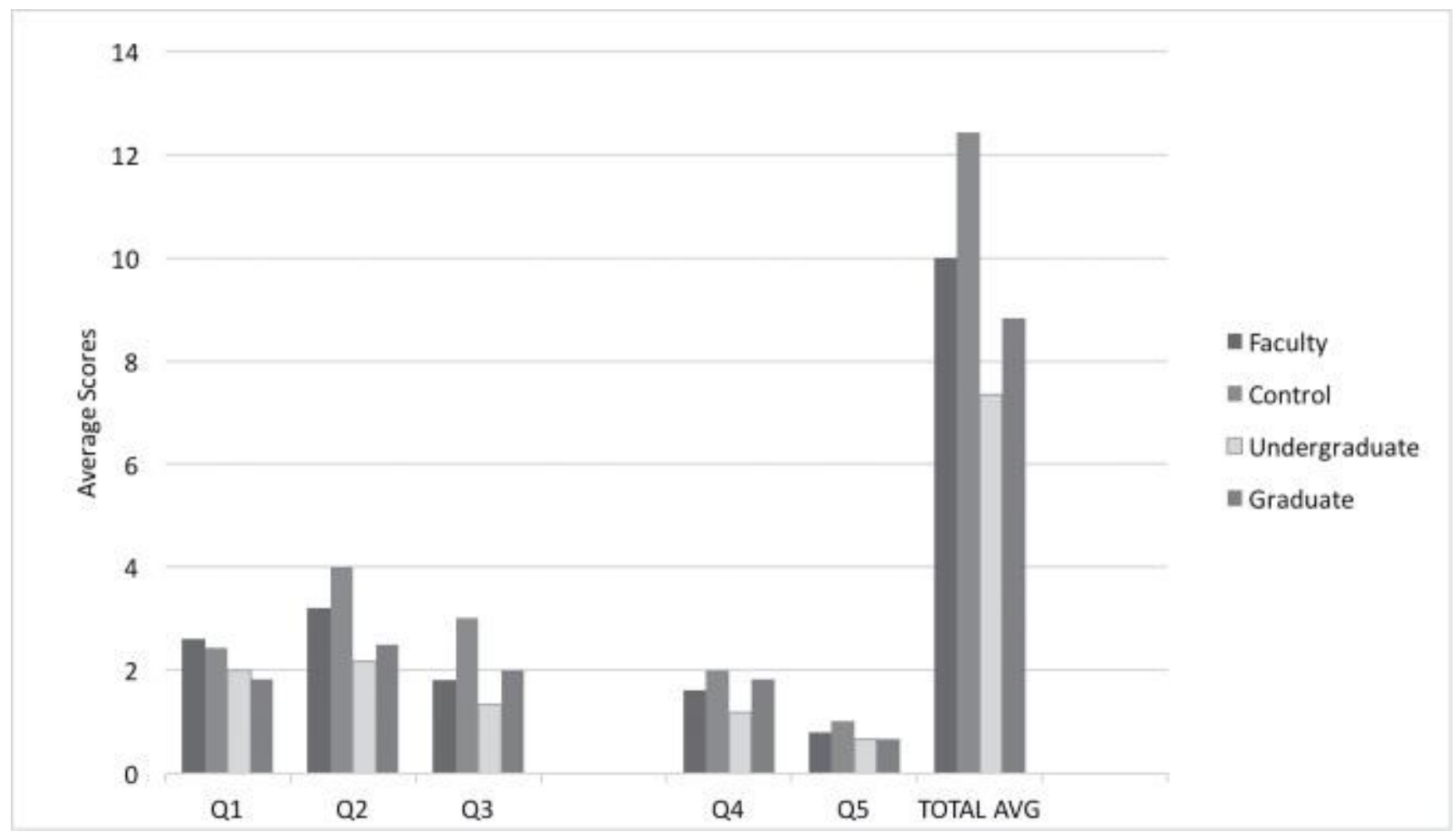

\section{Usability test scores with a comparison of performance averages by user groups}

As for student participants, the team noted that some were non-native English speakers, and the directions and questions were a language barrier for these users. Research has shown that the greatest source of library anxiety for non-native English speakers is the need to search and use English-language materials and resources (Shoham and Mizrachi 2001), and library terminology is considered a "third language" (Kamhi-Stein and Stein 1998, 174). Through the screen captures, the team observed undergraduates having the most difficulty accessing the e-journals collection and specific databases, with graduate students faring slightly better. For Question 2, users must locate the date range for the e-journal Scientific American. Two out of six undergraduates received a perfect score on this task, whereas three out of six graduate students received a perfect score. Graduate students were 21 percent more successful at completing this activity than undergraduates. The faculty group performed better as 80 percent (four out of five) were able to complete Question 2. One hundred percent (seven out of seven) of the control group were able to complete Question 2 perfectly (see Table 1). Students may not yet have been trained to differentiate between these resources or how to locate them. The team recognized the need for more intensive outreach to this population.

One salient example of undergraduate unfamiliarity with research information and library services was observed while participants were seeking an answer to Question 5, "Where do 
you get help with a research question?" Two out of six survey participants navigated away from the library Web site to the SBU homepage and then to the SBU Research Foundation page (a non-library page that does not offer access to databases, e-journals, or other library resources and services). Two out of six undergraduate participants were not able to locate research help; this percentage was the same for graduate student participants.

The research team also noted that five out of 18 non-control group participants (more than 25 percent) were not able to successfully locate help from the site, four of which were graduate and undergraduate students (see Table 1). Researchers noted that both more help options and more prevalent links would be needed to assist patrons. As for overall time on task, the control group averaged the fastest completion time of 00:04:06, followed by graduate students (00:05:05), undergraduates (00:07:02), and faculty, taking the longest time of 00:09:25 (see Table 1).

Faculty varied in their interest in the new product. One faculty member displayed frustration with the EDS as this was not her preferred method of research. She did reflect on the importance of electronic resources as she requires use of research databases for assignments and regularly requests library resource instruction for her students. Others felt this service would help those that were just beginning their research or just learning how to use the library resources, as the EDS provided a singular search option for users. A faculty participant felt that upper-level graduate students and professors are better served searching individual databases as they are familiar with the specific databases or sources that will target their research needs. She mentioned that the EDS search function might take longer to sift through because of the multitude of results returned.

Several student participants (and all the graduate student participants) were computer science majors. Several of their comments indicated they enjoyed the singular search option instead of needing to locate specific links on the homepage. A participant mentioned that she regularly used the SBU Library Web site for research and felt comfortable with the new interface. She stated that it made the research process more streamlined, but she could still easily access the resources she was accustomed to using.

\section{Discussion}

The findings show a need for online research support and information literacy instruction. One hazard for undergraduate researchers is that they do not know what they do not know, and will uncritically accept an incorrect or incomplete result of a research exercise (Holliday et al. 2015). Library Web site and search interface design must be informed by the library's information literacy program. There is evidence that undergraduate researchers prefer and perform more effective research when offered a convenient "Google-like" single-search box experience (Connaway, Dickey, and Radford 2011). However, a single-search box discovery tool on a library homepage is a more complex research environment than Google. Undergraduate participants did not easily recognize the EDS single-search box. The results of our usability test indicate that undergraduates face significant challenges in performing effective online research and library resource discovery due in part to a general unfamiliarity with distinctions between different library search and non-library interfaces and the 
resources and information these interfaces access. Overall, graduate student participants performed better than undergraduates except in the area of getting research help. The results of our usability testing underscore the conclusion that in general, undergraduates require training in information literacy practices in order to be effective online researchers, including knowing how and where to get research help. Graduate students demonstrate effectiveness as researchers but are no better than undergraduates at getting help when needed.

Faculty and graduate students benefitted from being experienced, practiced researchers. Their general familiarity with the online tools and framework of research was evident in the screen captures of their performance, and was articulated in their comments. One faculty participant stated that she was "not looking for a Google-like [research experience]." Through learning or practice, faculty and graduate students overall demonstrate a more effective process for engaging, solving, and reasonably evaluating the results of a research question.

An important distinction between each of these groups, however, is the variance in time on task. Graduate students were second only to the control group in completion time, followed by undergraduates. Though faculty took the longest amount of time to complete the testing, they were more successful than both the undergraduates and graduate students at completing the overall activity. This finding suggests that faculty engage more thoroughly in the examination of new library resources (namely, the Web interface and the EDS) and understand the importance of devoting more time to task so they can effectively address their research needs. This finding not only provides insight into the searching strategies of faculty versus that of students, but also validates the need for targeted and comprehensive information literacy instruction for students at all levels.

\section{Conclusion and recommendations}

Academic library research interfaces are complex by design in order to (1) serve the myriad discovery needs of a broad range of users (from undergraduates to advanced, seasoned researchers) and (2) tap into and bring together metadata of many different resource types from thousands of different sources. EDS, and all discovery services, are meant to facilitate and enhance focused, quick, effective research. An operative difference between Google use and online research is purposeful focus. Most users transfer their expectations for a quick, convenient Google-like search experience to online research using library discovery tools and databases. Observations of undergraduates performing the usability test indicate that information literacy skills are critical for doing successful research, identifying and understanding the general value of different information types, and recognizing and evaluating the comparative quality of their results. Research and the materials of scholarship and scholarly communication (including peer-reviewed articles, scholarly books, and primary sources) are unfamiliar to undergraduate researchers. The challenges of creating an effective online library research portal include a critical measure of information literacy. 
As a result of our findings, the research team made three recommendations for enhancing the online user experience. (1) Include systematic and comprehensive information literacy instruction not only as a part of traditional library course-integrated instruction, but also build information literacy principles into library Web site design and development, and all forms of reference service delivery. (2) Deliver online learning objects and resources that introduce and reinforce successful research skills, habits, and practices. (3) Incorporate relevant, meaningful examples of outcomes or other measures into EDS and the OPAC that will indicate to the user that she or he has performed a successful search transaction. Face-to-face course integrated library instruction sessions have traditionally included teaching research skills and practical applications of information literacy. Every opportunity should be taken to increase the reach and impact of course-integrated instruction, including outreach and collaboration with faculty. Information literacy learning objects should be strategically implemented throughout the library Web site and across the online research matrix (including EDS, research databases, ERMS, and subject guides), as well as other online spaces and communities.

Librarians have found and continue to find inconsistencies, confusion, and daunting complexity within the online research matrix. User-centered, information-literate Web design and development of library Web sites and search interfaces is essential for effective online research. EDS and other discovery tools are useful, but there is no universal "Google-like" research experience that will serve and satisfy the research needs of all users. Developers and vendors of discovery services must continually learn from their users and expand their services in order to meet and exceed the vast and varied needs of library users. A storm changes an environment. Though some things may be swept away or lost, the resultant environment becomes fertile ground for new growth and opportunity. 


\section{Appendix A}

\section{Usability Survey Rubric}

\section{Catalog}

Effectively search and discover titles in EDS catalog-only

Q: Does the library have a book titled "The World of the Druids"?

\begin{tabular}{lc}
\hline PROCESS & VALUE \\
\hline Does not use EDS / Clicks CATALOGS \& Uses & 1 \\
STARS & 2 \\
Uses EDS, but does not use Catalog Only & 3 \\
Uses EDS Catalog Only, does not limit to 'title' & 4 \\
Uses EDS Catalog Only, limits to 'title' & 0 \\
Other: & \\
Fails to find title &
\end{tabular}

2. eJournals \& eBooks $A$ to $Z$

Successfully searches for eJournals in eJournals \& eBooks $A$ to $Z$ Q: What is the date range for full-text access to the eJournal Scientific American?

\begin{tabular}{lc}
\hline PROCESS & VALUE \\
\hline Does not use EDS & 0 \\
Uses EDS & 1 \\
Uses EDS, limits to "title* & 2 \\
Clicks the link "eJOURNALs" & 3 \\
in the EDS Search box, uses eJournals \& eBooks A & \\
- Z and searches for Scientific American & \\
Identifies date range & 4 \\
Other: & \\
Fails to find title & 0 \\
\hline
\end{tabular}

\section{Databases}

Discovers selected research databases by subject

Q: Find a selection of databases for doing effective research in the Health Sciences.

\begin{tabular}{lc}
\hline PROCESS & VALUE \\
\hline Uses EDS to search for databases or health sciences, etc. & 0 \\
clicks the link 'DATABASES' in the EDS Search box, does not use SUBJECT & 1 \\
browse & 1 \\
Clicks DATABASES \& SUBJECT GUIDES on the & 2 \\
top menu, does click Databases A - Z, does not use SUBJECT browse & 2 \\
Clicks DATABASES \& SUBJECT GUIDES on the & 3 \\
top menu, does not click Databases A - Z & 3 \\
Clicks Health Sciences link on homepage icon & 3 \\
menu, does not find Health Sciences database & 3 \\
Clicks the link 'DATABASES' in the EDS Search box, does use SUBJECT browse & 3 \\
Clicks DATABASES \& SUBJECT GUIDES on the & \\
Clicks Health Sciences link on homepage icon & \\
menu, does find Health Sciences databases & \\
Other: &
\end{tabular}




\section{Peer-Reviewed Journal Article Discovery}

Discovers a peer-reviewed journal article

Q: Find a peer-reviewed journal article on sustainable agriculture.

\begin{tabular}{lc}
\hline PROCESS & VALUE \\
\hline Uses EDS, does not limit to peer reviewed & 1 \\
Uses EDS, does limit to peer reviewed & 2 \\
Other: & 0 \\
Fails to find peer-reviewed & 0 \\
\hline
\end{tabular}

\section{Getting Help}

Can effectively get help with online research

Q: Where do you get help with a research question?

\begin{tabular}{lc}
\hline PROCESS & VALUE \\
\hline Clicks the Ask Us button on the page header & 1 \\
Clicks the Answers \& Help link on the top menu & 1 \\
Clicks HELP link in Search box & 1 \\
Other: & 0 \\
Fails to get help &
\end{tabular}




\section{Appendix B}

Graduate Students' Results

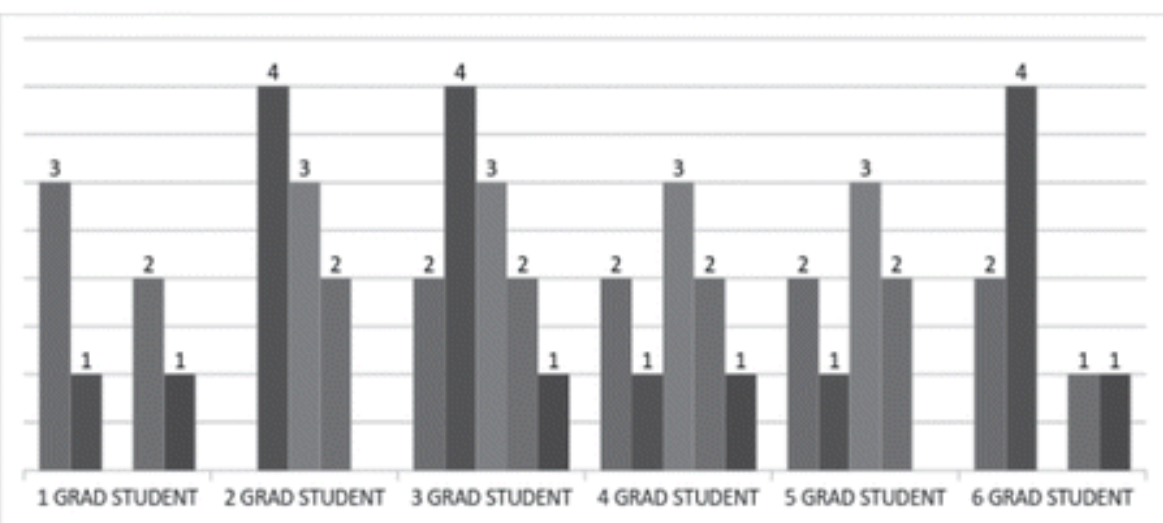

Undergraduates' Results
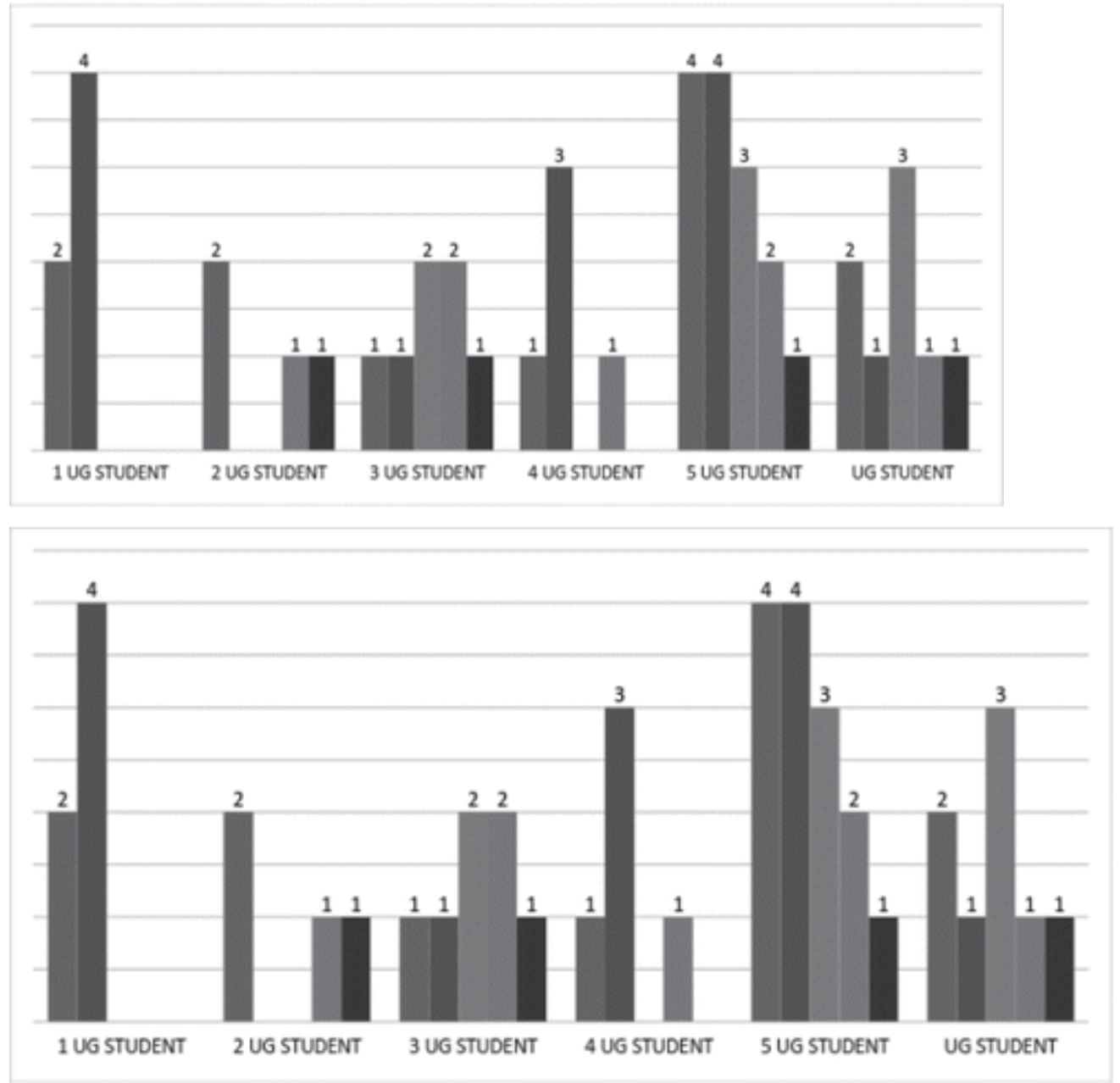

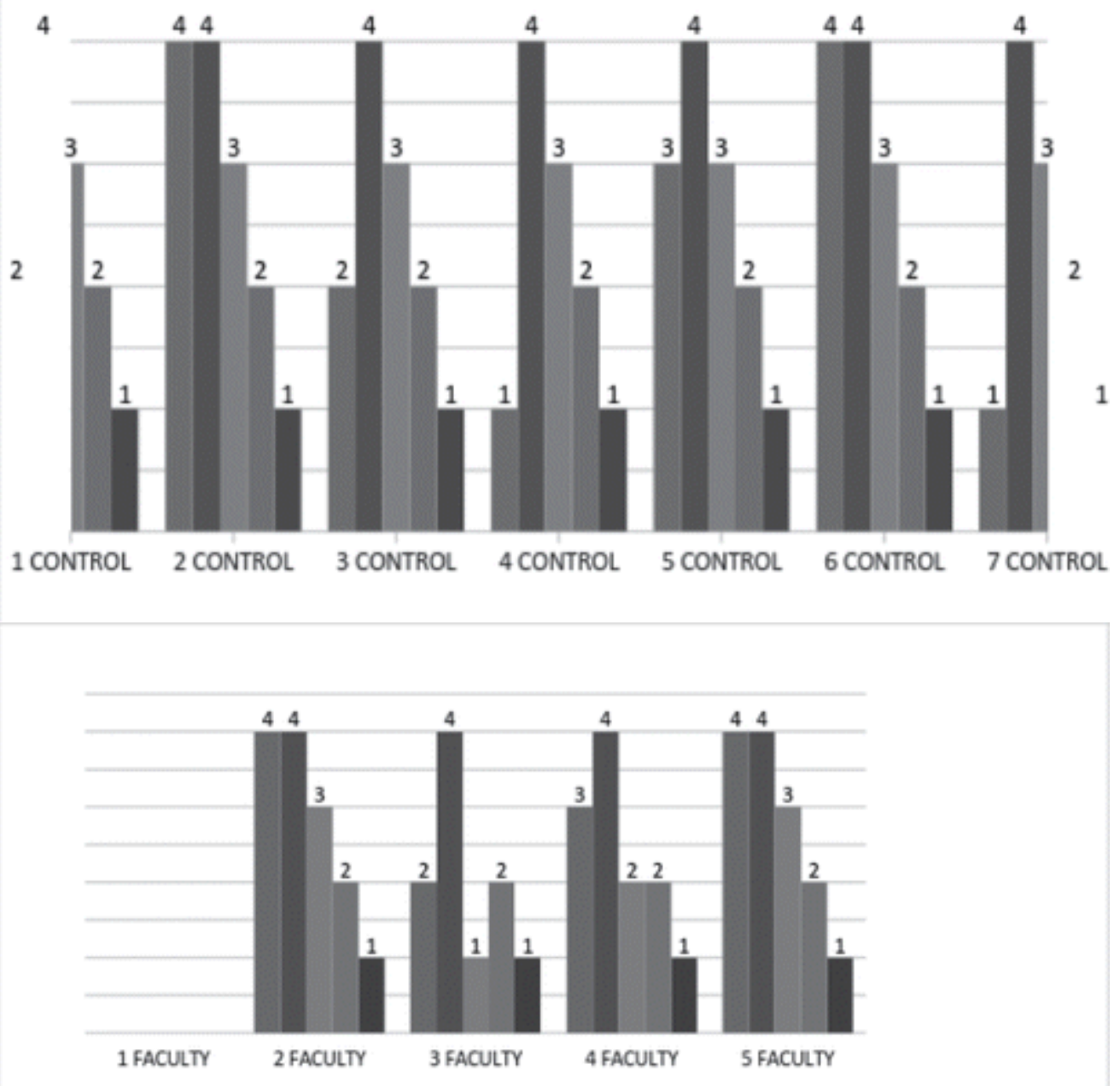


\section{References}

1. Ansari, M. N., and B. A. Zuberi. 2010. Use of electronic resources among academics at the University of Karachi. Library Philosophy and Practice (e-journal):385.

2. Brown, J. M., and M. Yunkin. (2014). Tracking Changes: One Library's Homepage Over Time---Findings from Usability Testing and Reflections on Staffing. Journal of Web Librarianship 8 (1):23-47.

3. Buck, S., and M. Mellinger. 2011. The impact of Serial Solutions' Summon ${ }^{\mathrm{TM}}$ on information literacy instruction: Librarian perceptions. Internet Reference Services Quarterly 16 (4):159-81. doi:10.1080/10875301.2011.621864. [Taylor \& Francis Online]

4. Cassidy, E. D., G. Jones, L. McMain, L. Shen, and S. Vieira. 2014. Student searching with EBSCO Discovery: A usability study.Journal of Electronic Resources Librarianship 26 (1):17-35.

doi:10.1080/1941126X.2014.877331. [Taylor \& Francis Online]

5. Connaway, L. S., T. J. Dickey, and M. L. Radford. 2011. If it is too inconvenient I'm not going after it: Convenience as a critical factor in information-seeking behaviors. Library \& Information Science Research 33 (3):179-90.

6. Fagan, J. C., M. Mandernach, C. S. Nelson, J. R. Paulo, and G. Saunders. 2012. Usability test results for a discovery tool in an academic library. Information Technology and Libraries 31 (1).

7. Gross, J., and L. Sheridan. 2011. Web scale discovery: The user experience. New Library World 112 (5/6):23647.

8. Holliday, W., B. Dance, E. Davis, B. Fagerheim, A. Hedrich, K. Lundstrom, and P. Martin. 2015. An information literacy snapshot: Authentic assessment across the curriculum. College \& Research Libraries 76 (2):170-87.

9. Kamhi-Stein, L. D., and A. P. Stein. 1998. Teaching information competency as a third language: A new model for library instruction. Reference \& User Services Quarterly 38 (2):173-79.

10. Kim, Y. M. 2010. The adoption of university library web site resources: A multigroup analysis. Journal of the American Society for Information Science and Technology 61 (5):978-93.

11. Luther, J., and M. C. Kelly. 2011. The next generation of discovery: The stage is set for a simpler search for users, but choosing a product is much more complex. Library Journal, 136 (5):66-71.

12. Olson, T. A. 2007. Utility of a faceted catalog for scholarly research. Library Hi Tech 25 (4):550-61.

13. Pinkas, M. M., M. Del Baglivo, I. R. Klein, E. Brown, R. Harris, and B. Gerhart. 2014. Selecting and implementing a discovery tool: The University of Maryland health sciences and human services library experience. Journal of Electronic Resources in Medical Libraries 11 (1):1-12.

doi:10.1080/15424065.2013.876574. [Taylor \& Francis Online]

14. Shoham, S., and D. Mizrachi. 2001. Library anxiety among undergraduates: A study of Israeli B. Ed students. The Journal of Academic Librarianship 27 (4):305-11.

15. Swanson, T. A., and J. Green. 2011. Why we are not Google: Lessons from a library web site usability study. The Journal of Academic Librarianship 37 (3):222-229.

16. Thompson, J. L., K. S. Obrig, and L. E. Abate. 2013. Web-scale discovery in an academic health sciences library: Development and implementation of the EBSCO Discovery Service. Medical Reference Services Quarterly 32 (1):26-41.

17. Thomsett-Scott, B., and P. E. Reese. 2012. Academic libraries and discovery tools: A survey of the literature. College \& Undergraduate Libraries 19 (2-4):123-43. 


\section{Author biographies}

Darren Chase is the Scholarly Communication Librarian for Stony Brook University Libraries. His research interests include online user experience, human computer interaction, scholarly communication, open access, and information literacy. Darren received a BA in English Literature from the University of Southern Mississippi and his MLIS from the University at Buffalo. Darren has Advanced Graduate Certification in Web Design and Development from the University of Denver.

Elizabeth Trapasso is a Visiting Assistant Librarian for the Stony Brook University Libraries. Elizabeth's research interests include information literacy teaching and assessment and usability testing. She received a Bachelor of Science Degree in Elementary Education from Boston University, a Master of Science in Education in Special Education, and Master of Science in Library and Information Science from Long Island University.

Robert Tolliver is the Head of Science and Engineering at the Stony Brook University Libraries. His research interests include science and engineering information, scholarly communication, and usability of library resources. He received his PhD in Geology from the University of Tennessee and his MLIS from the University of South Carolina. 